\title{
Reação de genótipos de milho à mancha ocular causada por Kabatiella zeae
}

\section{Reaction of corn genotypes to eyespot caused by Kabatiella zeae}

\author{
Rubia Cristiani Camochena ${ }^{1 *}$; Idalmir dos Santos ${ }^{2}$; Claudia Mantelii; \\ Gustavo Malagi ${ }^{3}$; Sérgio Miguel Mazaro ${ }^{4}$; Rosangela Dallemole-Giaretta ${ }^{5}$
}

\section{Resumo}

O objetivo deste trabalho foi avaliar a reação de genótipos de milho quanto à mancha ocular causada por Kabatiella zeae sob condições naturais de infecção. Os ensaios foram instalados na safra 2006/2007, no município de Pato Branco, PR, com 33 híbridos e com duas épocas de semeadura, dia 13/10 e 27/12/2006, respectivamente; e na safra 2007/2008, no mesmo município, com 10 híbridos e com duas épocas de semeadura, dia 20/10 e 12/11/2007, respectivamente e no município de Palma Sola, SC, com oito híbridos e com uma época de semeadura, dia 30/09/2007. A intensidade da doença foi determinada pela avaliação de severidade em todos os híbridos de milho, em diferentes estádios de desenvolvimento. As reações de milho observadas permitem separar estatisticamente genótipos com diferentes níveis de resistência à mancha ocular. Os híbridos AG 9020 e SPRINT apresentaram maior suscetibilidade à doença, e AS 1565 e DKB 234, maior resistência, repetindo este comportamento nos dois anos e épocas de cultivo. Concluiu-se que a variação na suscetibilidade à mancha ocular entre os híbridos de milho testados, pode ter sido influenciada pelas condições ambientais.

Palavras-chave: Doenças do milho, resistência genética

\begin{abstract}
The objective of this study was to evaluate the reaction of corn genotypes to eyespot caused by Kabatiella zeae under natural field conditions. The assay was carried out during the 2006/2007 growing season, in Pato Branco-Paraná State, consisting of 33 hybrids and two sowing seasons, on 10/13 and $12 / 27 / 2006$, respectively; and in the 2007/2008 growing season, in the same place, with 10 hybrids and two sowing seasons, on 10/20 and 11/12/2007, respectively, and in Palma Sola-Santa Catarina State, with 8 hybrids and one sowing season, on 09/30/2007. Disease intensity was determined by means of severity evaluations. The observed corn plant reactions allowed genotypes with different levels of eyespot resistance to be discriminated. Hybrids AG 9020 and SPRINT were the most susceptible to the disease, while AS 1565 and DKB 234 were the most resistant; this behavior was repeated in both years and growing seasons. It was concluded that the variation in susceptibility to eyespot among the hybrids tested, may have been influenced by ambient conditions.
\end{abstract}

Key words: Corn diseases, genetic resistance

1 Bolsista do Programa Paranaense de Certificação de Produtos Orgânicos. Universidade Tecnológica Federal do Paraná, UTFPR. Pato Branco. E-mail: rubia.agro@gmail.com

2 Prof. Adjunto de Fitopatologia da UTFPR. Pato Branco. E-mail: idalmir@utfpr.edu.br

3 Mestrandos em Agronomia, Produção Vegetal. UTFPR. Pato Branco. E-mail: claudiamanteli@hotmail.com; malagi@agronomo. eng.br

4 Prof. Adjunto de Fitopatologia. UTFPR. Dois Vizinhos. E-mail: sergio@utfpr.edu.br

5 Prof ${ }^{\mathrm{a}}$ Colaboradora Universidade do Centro Oeste do Paraná, UNICENTRO. Guarapuava, PR. E-mail: rodallemole@yahoo. com.br

* Autor para correspondência 


\section{Introdução}

A partir da década de 90, com o aumento das áreas de cultivo de milho e a introdução de novos cultivares, com diferentes níveis de resistência, observou-se o aumento da ocorrência e da severidade das doenças foliares fúngicas desta cultura.

No oeste de Santa Catarina e sudoeste do Paraná, a mancha ocular, causada por Kabatiella zeae ( $K$. zeae) Narita \& Hiratsuka (Dingley), vem ganhando importância devido à alta severidade que tem apresentado em diversos híbridos comerciais, desde a safra 2004/2005 (CAMOCHENA; SANTOS; MALAGI, 2007). Esta doença foi descrita pela primeira vez no Japão por Narita e Hiratsuka em 1959 (REIFSCHNEIDER; ARNY, 1983), e desde então, o patógeno se disseminou para várias áreas do mundo (CHIANG; HUDSON, 1990). No Brasil, a doença foi relatada no ano agrícola 1982/83, em Dourados-MS (ESTEVES, 1984) sob condições de infestação natural. Somente vinte anos após este relato, foi confirmada sua presença, na safra de 2004/05, em Santa Catarina e no Paraná, após o isolamento do fitopatógeno em meio de cultivo a partir de material vegetal de quinze híbridos de milho com posterior identificação (SANTOS; CAMOCHENA; MALAGI, 2007a; SANTOS; SILVA; MALAGI, 2007b).

Os sintomas da doença caracterizam-se por pequenas manchas, rodeadas por um círculo pardo e com halo amarelo, semelhante a um olho, e quando observadas contra a luz, apresentam aspecto translúcido, encharcado. No início da doença, as manchas são raras, mas logo aumentam, podendo coalescer ocupando totalmente o limbo foliar eventualmente a palha da espiga. Sob condições de alta umidade e temperaturas amenas, os órgãos afetados tornam-se amarelados e secam prematuramente (REIFSCHNEIDER; ARNY, 1983).

Nos Estados Unidos, Reifschneider e Arny (1983) relatam danos de até 50\% com inoculação artificial e 9\% com inoculação natural, em cultivares suscetíveis. Além disso, salientam que plantas infectadas por $K$. zeae têm a área fotossintética diminuída, apresentando-se mais predispostas à podridão do colmo e da raíz. Entretanto, para mancha ocular, nenhum estudo foi realizado quanto a este quesito no País, embora observações no campo mostrem a severidade com que ela vem ocorrendo em alguns híbridos.

A literatura internacional, com exceção de alguns trabalhos (REIFSCHNEIDER; ARNY, 1983; NAIBO; THIERRY, 1999), não fornece informações suficientes para a compreensão de todos os aspectos do patossistema K. zeae em milho, sendo que no Brasil as investigações encontramse nas etapas iniciais (SANTOS; CAMOCHENA; MALAGI, 2007a; SANTOS; SILVA; MALAGI, 2007b). Salienta-se a importância de conhecer o nível de resistência à mancha ocular de genótipos de milho que poderão ser empregados como progenitores de resistência em cruzamento com materiais suscetíveis.

O presente trabalho teve por objetivo avaliar a reação de genótipos de milho quanto à mancha ocular causada por $K$. zeae em condições naturais de infecção.

\section{Materiais e Métodos}

Os trabalhos referentes à reação de genótipos de milho à mancha ocular foram realizados em diferentes anos de cultivos, épocas de semeadura e locais, em áreas sob sistema de semeadura direta. Os ensaios foram instalados na safra 2006/2007 e 2007/2008 no município de Pato Branco, PR, em duas épocas. Na última safra também foi instalado outro experimento em Palma Sola, SC, em uma época apenas. Para a safra de 2006/2007, em Pato Branco, as semeaduras foram realizadas em uma área de sucessão de culturas milho e trigo, nos dias 13 de outubro e 27 de dezembro. Para a safra $2007 / 2008$, as semeaduras foram realizadas nos dias 20 de outubro e 12 de novembro, em Pato Branco, e no dia 30 de setembro, em Palma Sola. Nesta safra, 
as áreas utilizadas em ambos os municípios haviam sido cultivadas anteriormente com soja, seguida de trigo no inverno.

No município de Pato Branco, os ensaios foram conduzidos na área experimental da Universidade Tecnológica Federal do Paraná, campus Pato Branco, em solo pertencente à unidade de mapeamento Latossolo Vermelho Distroférrico Úmbrico, textura argilosa, álico, fase floresta subtropical perenifólia, com relevo ondulado (BHERING et al., 2008), em latitude $26^{\circ} 10^{\prime} 38^{\prime \prime} \mathrm{S}$ e longitude $52^{\circ} 41^{\prime} 24^{\prime \prime} \mathrm{W}$, a 780 metros de altitude. O clima local é do tipo Cfa- temperado húmido com verão quente, com temperatura média no mês mais frio inferior a 18 ${ }^{\circ} \mathrm{C}$ (mesotérmico) e temperatura média no mês mais quente acima de $22{ }^{\circ} \mathrm{C}$, com geadas pouco freqüentes no inverno e tendência de concentração das chuvas nos meses de verão (Classificação de Koppen), com precipitação anual média que varia de 2000 a $2500 \mathrm{~mm}$ (CAVIGLIONE et al., 2000). No município de Palma Sola, os ensaios foram instalados em Latossolo Bruno Distrófico, textura argilosa, com cobertura vegetal originária de florestas e campos. Possui latitude de $26^{\circ} 20^{\prime} 51^{\prime \prime} \mathrm{S}$ e a uma longitude $53^{\circ} 16^{\prime} 42^{\prime \prime} \mathrm{O}$, a 870 metros de altitude. O clima é mesotérmico úmido, com verões quentes e invernos rigorosos, com temperaturas médias de $17,4^{\circ} \mathrm{C}$, e precipitação anual média de 1900 a $2500 \mathrm{~mm}$ (PREFEITURA MUNICIPAL DE PALMA SOLA, 2009).

$\mathrm{O}$ delineamento experimental utilizado foi o de blocos ao acaso com três repetições, sendo a unidade experimental constituída por cinco linhas de cultivo de cinco metros de comprimento cada, espaçadas em $0,8 \mathrm{~m}$, contendo seis plantas por metro linear, totalizando 75 mil plantas por ha. Na safra 2006/2007 foram testados 33 híbridos, e na safra 2007/2008 testaram-se 10 híbridos no município de Pato Branco, e oito no município de Palma Sola (Tabela 1). Em todos os ensaios foi utilizada uma semeadora para incorporação do adubo e após, realizando-se em seguida a semeadura manual dos diferentes materiais genéticos. A aplicação do adubo nitrogenado (uréia) foi realizada em duas etapas: quando as plantas apresentavam três e cinco folhas verdadeiras, respectivamente. A caracterização dos estádios fenológicos do milho foi baseada na escala Agroceres (1996), adaptada por Dourado Neto e Fancelli (2000).

A avaliação da severidade da doença em Pato Branco foi realizada aos 110 e aos 75 dias após a semeadura (DAS), para primeira e segunda épocas respectivamente, no primeiro ano de cultivo e aos 74 DAS, para primeira e segunda época no segundo ano. Em Palma Sola, as avaliações foram realizadas aos 131 d.a.s. Para avaliação foram coletadas aleatoriamente 4 plantas por parcela, considerandose todas as folhas de cada planta e utilizando uma escala diagramática para avaliação da severidade da mancha ocular em milho desenvolvida por Camochena, Santos e Mazaro (2008).

Os dados meteorológicos como pluviosidade expressa em $\mathrm{mm}$, e temperatura expressa em graus centígrados, foram coletados diariamente, calculando-se as médias a cada cinco dias durante os períodos de cultivo (Figuras 1A e 1B).

Os dados obtidos pela avaliação de severidade foram submetidos à análise de variância e as médias comparadas pelo teste de Scott-Knott ao nível de $5 \%$ de probabilidade de erro tipo I, classificando assim, a reação dos híbridos de milho testados para a mancha ocular em baixa, intermediária e alta suscetibilidade, em função do agrupamento das médias da severidade da doença baseados na análise estatística. 
Tabela 1. Genótipos de milho utilizados nas safras 2006/07 e 2007/08, nos municípios de Pato Branco, PR, e Palma Sola, SC.

\begin{tabular}{|c|c|c|c|c|c|}
\hline \multicolumn{6}{|c|}{ - } \\
\hline Materiais & Tipo* & Ciclo* & Materiais & Tipo* & Ciclo* \\
\hline AG 8021 & HS & $\mathrm{P}$ & BALU 761 & HD & $\mathrm{P}$ \\
\hline AG 9020 & HS & SP & BD 7912 & HS & $\mathrm{P}$ \\
\hline AG 2020 & HD & $\mathrm{P}$ & CARGO & HD & $\mathrm{P}$ \\
\hline AGN 30A06 & HS & SP & DKB 214 & HS & $\mathrm{P}$ \\
\hline AGN 2012 & HD & SP & DKB 234 & HS & SP \\
\hline AGN 35A42 & HD & SP & DKB 566 & HT & $\mathrm{P}$ \\
\hline AS 32 & HD & $\mathrm{P}$ & DKB 950 & HS & $\mathrm{P}$ \\
\hline AS 1545 & HS & $\mathrm{P}$ & DKB 979 & HD & $\mathrm{P}$ \\
\hline AS 1565 & HS & $\mathrm{P}$ & PENTA & HS & $\mathrm{P}$ \\
\hline AS 1560 & HS & $\mathrm{P}$ & PREMIUM FLEX & HS & $\mathrm{P}$ \\
\hline AS 1570 & HS & $\mathrm{P}$ & SG 150 & HT & $\mathrm{P}$ \\
\hline AS 3466 & HT & $\mathrm{P}$ & SG 6418 & HT & $\mathrm{P}$ \\
\hline ATTACK & $\mathrm{HSm}$ & $\mathrm{P}$ & SPRINT & HS & $\mathrm{HP}$ \\
\hline AX 890 & HS & SP & $30 \mathrm{~F} 53$ & HS & $\mathrm{P}$ \\
\hline AX 892 & HS & SP & $30 \mathrm{R} 50$ & HS & $\mathrm{P}$ \\
\hline AX 895 & HT & $\mathrm{P}$ & $32 \mathrm{R} 21$ & HS & SP \\
\hline BALU 184 & HD & $\mathrm{P}$ & - & - & - \\
\hline \multicolumn{3}{|c|}{---------- Safra 2007/08 Palma Sola, SC ---------- } & \multicolumn{3}{|c|}{----- Safra 2007/08 Pato Branco, PR ----- } \\
\hline AG 8011 & HT & $\mathrm{P}$ & AG 8011 & HT & $\mathrm{P}$ \\
\hline AG 9020 & HS & SP & AG 9020 & HS & SP \\
\hline AS 1565 & HS & $\mathrm{P}$ & AS 1565 & HS & $\mathrm{P}$ \\
\hline DKB 234 & HS & SP & DOW 2A106 & HS & SP \\
\hline DKB 566 & HT & $\mathrm{P}$ & DOW 2A120 & HS & HP \\
\hline SG 150 & HT & $\mathrm{P}$ & DKB 234 & HS & SP \\
\hline SPRINT & HS & HP & DKB 566 & HT & $\mathrm{P}$ \\
\hline 30F53 & HS & $\mathrm{P}$ & SG 150 & HT & $\mathrm{P}$ \\
\hline- & - & - & SPRINT & HS & $\mathrm{HP}$ \\
\hline- & - & - & $30 \mathrm{~F} 53$ & HS & $\mathrm{P}$ \\
\hline
\end{tabular}

*TIPO:HS-híbrido simples; HSm-híbrido simples modificado; HD-híbridoduplo; HT-híbrido triplo *CICLO: P-precoce; SP-super-precoce; HP-hiper-precoce

Fonte: Associação Paulista de Produtores de Sementes, 2008. 


\section{Resultados e Discussão}

No primeiro ano de cultivo, safra de 2006/2007, em Pato Branco, na primeira época, constatouse alta severidade da doença no campo, com diferenças significativas entre os genótipos de milho testados (Tabela 2). Os que apresentaram baixa suscetibilidade foram AGN 30A06, CARGO, ATTACK, PIONEER 30R50, PIONEER 30F53 e AS1565 por apresentarem severidade de 6,2 a $7,5 \%$ e os mais suscetíveis à doença foram SPRINT, AG 9020 e SG 150, apresentando severidade de 15,8 a $17,2 \%$, Assim, dos 33 materiais testados na primeira época da safra 2006/2007, 9\% foram considerados altamente suscetíveis, $18 \%$ de suscetibilidade intermediária e os demais apresentaram baixa suscetibilidade variando de 8,43 a $13,80 \%$, sendo que, estatisticamente, foi possível diferenciar em grupos os híbridos de milho testados (a-alta suscetibilidade; b,c-suscetibilidade intermediária; d-baixa suscetibilidade) (Tabela 2). Em todos os ensaios, observou-se que nenhum dos materiais testados foi imune à K. zeae (Tabela 2).

Na segunda época de cultivo, os híbridos que se destacaram entre os de baixa suscetibilidade foram PIONEER 30R50, PIONEER 30F53 e AS1565, sendo ainda complementados pelos hibridos AS 1560, AG 8021, BD 7912, 32R21, DKB 214, AX 892 e ainda DKB 234. AG9020 e SPRINT foram confirmados como altamente suscetíveis. Os primeiros sintomas foram obervados visualmente aos 35 dias após o plantio, no entanto, a pressão de doença ao longo do cultivo e no momento da avalação foi $40 \%$, em média, menor do que na primeira época, fato que contribuiu para aumentar o número de genótipos que se diferenciaram entre os mais resistentes.

Nesta época de cultivo, a severidade da doença, avaliada no estádio de florescimento e polinização, esteve próxima de $7 \%$ para os híbridos altamente suscetíveis e 2,23\% para os materiais com baixa suscetibilidade. As condições climáticas foram carcterizadas por uma precipitação de $52,5 \mathrm{~mm}$ e 21,2 ${ }^{\circ} \mathrm{C}$ de temperatura média, nos quinze dias que antecederam a avaliação de severidade (Figura 1A).

Na safra 2007/2008, na primeira época de cultivo, embora tenha se observado a baixa intensidade da doença, verificou-se novamente o comportamento de alta suscetibilidade à mancha ocular, para o híbrido AG 9020. Além disso, houve a confirmação dos híbridos AS 1565, DKB 234 e PIONEER 30F53, apresentando-se com baixa suscetibilidade à doença (a-altamente suscetível; b-suscetibilidade intermediária; c-baixa suscetibilidade) (Tabela 2). Os primeiros sintomas foram observados aos 16 dias após a semeadura, contudo, a pressão da doença, durante o período de cultivo até o momento da avaliação de severidade, foi menor do que na primeira época da primeira safra. A severidade da doença, avaliada no estado de florescimento e polinização, foi de 3,6 e 0,83 a 1,83 para os híbridos altamente suscetíveis e com baixa suscetibilidade, respectivamente. Durante os quinze dias de cultivo que antecederam à avaliação de severidade, as condições climáticas caracterizaram-se por uma precipitação acumulada de $94,3 \mathrm{~mm}$ e $21,6^{\circ} \mathrm{C}$ de temperatura média (Figura 1B).

A segunda época de cultivo novamente confirmou o híbrido AG 9020 como o mais suscetível à mancha ocular. Entre os materiais com baixa suscetibilidade estão o SG 150, AS 1565, DKB 234, DOW 2A120, PIONER 30F53 e DOW 2A106, com o mesmo comportamento observado na primeira época desta safra (Tabela 2). Os primeiros sintomas foram observados aos nove dias após a semeadura, podendo ter sido influenciados pela alta precipitação, de 102,2 mm, que ocorreu durante esse período e temperatura média de $20^{\circ} \mathrm{C}$ (Figura 1B).

Apesar do rápido aparecimento dos sintomas, a doença progrediu lentamente, com baixa pressão durante o período de cultivo. A severidade observada, no estádio de florescimento e polinização, foi de 3,8 e 1 a 1,3\% nos híbridos alta suscetibilidade e baixa suscetibilidade, respectivamente. Durante os quinze dias que antecederam a avaliação de severidade, a precipitação acumulada foi de $47,8 \mathrm{~mm}$ e $22,1^{\circ} \mathrm{C}$ de temperatura média (Figura 1B). Com relação aos 
dados meteorológicos, observa-se que nesta época à primeira época do primeiro ano de cultivo, houve diminuição na precipitação acumulada e influenciando novamente no desenvolvimento da leve descrécimo na temperatura média em relação doença.

Tabela 2. Severidade da mancha ocular em genótipos de milho avaliados na safra 2006/2007, em 13/10/2006 (Época 1) e 27/12/2006 (Época 2), no município de Pato Branco, PR e na safra 2007/2008 no município Pato Branco, PR, 20/10/2007 (Época 1) e 12/11/2007 (Época 2), e em época única no município de Palma Sola, SC, em 30/09/2007.

\begin{tabular}{|c|c|c|c|c|c|}
\hline \multicolumn{3}{|c|}{ Safra 2006/07 Pato Branco, PR } & \multicolumn{3}{|c|}{ Safra 2007/08 Pato Branco, PR } \\
\hline Genótipos & Época $1 *$ & Época 2* & Genótipos & Época $1 *$ & Época $2 *$ \\
\hline AG 2020 & $10,10 \mathrm{c}$ & $3,95 \mathrm{~b}$ & AG 8011 & $1,33 \mathrm{~b}$ & $1,83 \mathrm{~b}$ \\
\hline AG 8021 & $8,85 \mathrm{c}$ & $2,62 \mathrm{~d}$ & AG 9020 & $3,60 \mathrm{a}$ & $3,83 \mathrm{a}$ \\
\hline AG 9020 & 16,87 a & $7,12 \mathrm{a}$ & AS 1565 & $0,83 \mathrm{~b}$ & $1,00 \mathrm{c}$ \\
\hline AGN 2012 & $10,83 \mathrm{c}$ & $3,96 \mathrm{~b}$ & DOW 2A106 & $1,00 \mathrm{~b}$ & $1,17 \mathrm{c}$ \\
\hline AGN 30A06 & $.7,49 \mathrm{~d}$ & $3,33 \mathrm{c}$ & DOW 2A120 & $1,00 \mathrm{~b}$ & $1,33 \mathrm{c}$ \\
\hline AGN $35 \mathrm{~A} 42$ & $10,20 \mathrm{c}$ & $3,99 \mathrm{~b}$ & DKB 234 & $0,67 \mathrm{~b}$ & $1,00 \mathrm{c}$ \\
\hline AS 32 & $8,64 \mathrm{c}$ & $4,93 \mathrm{~b}$ & DKB 566 & $1,17 \mathrm{~b}$ & $2,00 \mathrm{~b}$ \\
\hline AS 1545 & $10,62 \mathrm{c}$ & $3,53 \mathrm{c}$ & SG 150 & $1,17 \mathrm{~b}$ & $1,00 \mathrm{c}$ \\
\hline AS 1560 & $8,95 \mathrm{c}$ & $2,72 \mathrm{~d}$ & SPRINT & $1,83 \mathrm{~b}$ & $2,50 \mathrm{~b}$ \\
\hline AS 1565 & $6,20 \mathrm{~d}$ & $2,24 \mathrm{~d}$ & $30 F 53$ & $1,00 \mathrm{~b}$ & $1,00 \mathrm{c}$ \\
\hline AS 1570 & $8,95 \mathrm{c}$ & $3,73 \mathrm{~b}$ & - & - & - \\
\hline AS 3466 & $10,93 \mathrm{c}$ & $3,78 \mathrm{~b}$ & - & - & - \\
\hline ATTACK & $6,45 \mathrm{~d}$ & $4,18 \mathrm{~b}$ & - & - & - \\
\hline AX 890 & - & $4,79 \mathrm{~b}$ & - & - & - \\
\hline AX 892 & $12,48 \mathrm{~b}$ & $1,95 \mathrm{~d}$ & - & - & - \\
\hline AX 895 & $12,28 \mathrm{~b}$ & $3,62 \mathrm{c}$ & - & - & - \\
\hline BD 7912 & $10,41 \mathrm{c}$ & $2,39 \mathrm{~d}$ & - & - & - \\
\hline BALU 184 & $8,85 \mathrm{c}$ & $3,37 \mathrm{c}$ & - & - & - \\
\hline BALU 761 & $9,89 \mathrm{c}$ & $3,33 \mathrm{c}$ & - & - & - \\
\hline CARGO & $6,56 \mathrm{~d}$ & $5,20 \mathrm{~b}$ & - & - & - \\
\hline DKB 214 & $8,43 \mathrm{c}$ & $2,20 \mathrm{~d}$ & - & - & - \\
\hline DKB 234 & $13,74 \mathrm{~b}$ & $1,88 \mathrm{~d}$ & CV\% & 12,08 & 11,36 \\
\hline DKB 566 & $13,74 \mathrm{~b}$ & $5,18 \mathrm{~b}$ & & & \\
\hline DKB 950 & $9,58 \mathrm{c}$ & $3,95 \mathrm{~b}$ & \multicolumn{3}{|c|}{ Safra 2007/08 Palma Sola, SC } \\
\hline DKB 979 & $9,57 \mathrm{c}$ & - & \multicolumn{3}{|c|}{ Época única* } \\
\hline P. FLEX & $8,64 \mathrm{c}$ & $4,33 \mathrm{~b}$ & AG8011 & \multicolumn{2}{|c|}{$1,37 \mathrm{c}$} \\
\hline PENTA & $10,83 \mathrm{c}$ & $4,53 \mathrm{~b}$ & AG9020 & \multicolumn{2}{|c|}{$11,13 \mathrm{a}$} \\
\hline SG 150 & 15,82 a & $3,11 \mathrm{c}$ & AS1565 & \multicolumn{2}{|c|}{$0,89 \mathrm{c}$} \\
\hline SG 6418 & $11,87 \mathrm{~b}$ & $3,85 \mathrm{~b}$ & DKB234 & \multicolumn{2}{|c|}{$2,08 \mathrm{c}$} \\
\hline SPRINT & 17,18 a & $6,99 \mathrm{a}$ & DKB566 & \multicolumn{2}{|c|}{$1,88 \mathrm{c}$} \\
\hline $30 \mathrm{~F} 53$ & $6,29 \mathrm{~d}$ & $2,56 \mathrm{~d}$ & SG150 & \multicolumn{2}{|c|}{$6,82 \mathrm{~b}$} \\
\hline $30 \mathrm{R} 50$ & $6,45 \mathrm{~d}$ & $1,33 \mathrm{~d}$ & SPRINT & \multicolumn{2}{|c|}{$12,27 \mathrm{a}$} \\
\hline $32 \mathrm{R} 21$ & $9,68 \mathrm{c}$ & $2,32 \mathrm{~d}$ & $30 \mathrm{~F} 53$ & \multicolumn{2}{|c|}{$1,34 \mathrm{c}$} \\
\hline $\mathrm{CV} \%$ & 14,83 & 23,23 & & \multicolumn{2}{|c|}{11,5} \\
\hline
\end{tabular}

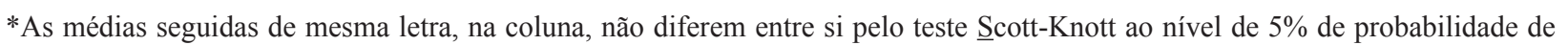
erro tipo I.

Fonte: Elaboração dos autores. 
A grande pressão da doença, na safra 2006/2007, na primeira época de cultivo se deve provavelmente às condições climáticas mais propícias à doença, com temperaturas mais amenas e chuvas mais regulares. A maior precipitação pluviométrica ocorreu a partir da segunda quinzena de dezembro, (Figura 1A), sendo que nos quinze dias que antecederam as avaliações da severidade houve um acumulado de chuva de $181 \mathrm{~mm} \mathrm{e} 23,1^{\circ} \mathrm{C}$ de temperatura média. Os primeiros sintomas da doença foram observados aos
37 dias após a semeadura (d.a.s.), quando as plantas apresentavam oito folhas totalmente expandidas.

Esses resultados evidenciam a importância da doença no Sudoeste do Paraná e Oeste de Santa Catarina, de modo que ela manifestou-se em vários híbridos de milho, e com alta severidade. Assim, os danos para a cultura do milho poderão se tornar expressivos em condições ideais para o patógeno. Apesar disso, não há estudos epidemiológicos informando as amplitudes climáticas ideais para este patossistema.

Figura 1. As barras representam as médias de temperatura $\left(\mathrm{T}^{\circ} \mathrm{C}\right)$ e a linha representa o somatório da precipitação pluviométrica (mm) obtido a cada cinco dias, na safra 2006/2007 (A) e na safra 2007/2008 (B) no município de Pato Branco, PR, e na safra 2007/2008 (C) no município de Palma Sola, SC.
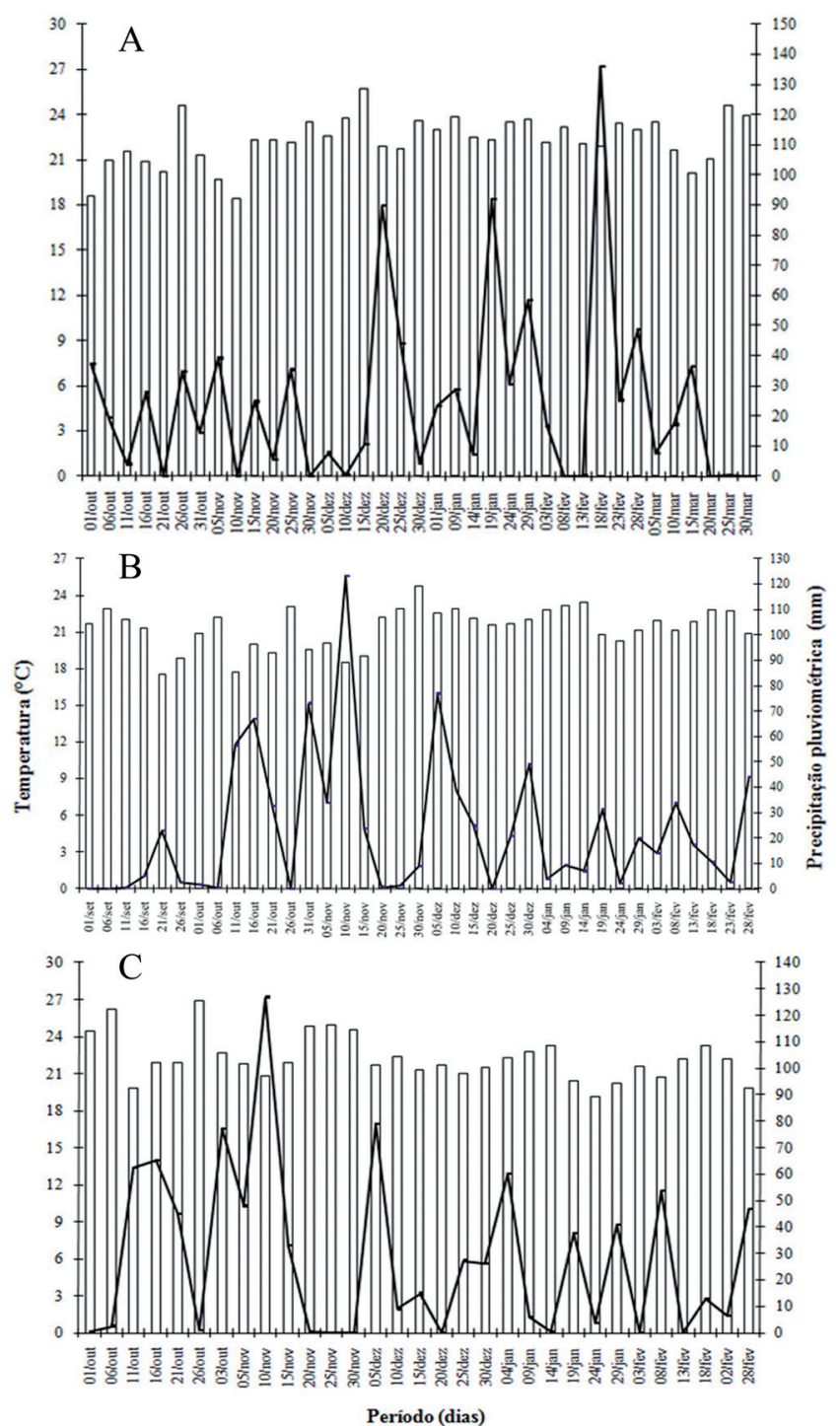

Fonte: Elaboração dos autores. 
$\mathrm{O}$ fator que possivelmente determinou a menor intensidade da doença, na segunda época do primeiro ano de cultivo, foi o menor índice de pluviosidade e sua distribuição irregular, em relação à primeira época (Figuras 1A e 1B), associado, possivelmente, à menor quantidade de inóculo de $K$. zeae presente nos restos culturais de milho, nesta área de cultivo.

Diferenças de suscetibilidade à mancha ocular entre híbridos de milho, sob infecção natural, avaliados por três anos consecutivos, também foram constatadas por Pronczuk, Bojanowski e Warzechaj (2004). Segundo estes autores, a ocorrência e a intensidade da mancha ocular, no campo, foram influenciadas pelas condições ambientais.

Outra hipótese a ser considerada seria a de que o patógeno foi transmitido pelas sementes contaminadas, no caso do segundo ano de cultivo. Esta hipótese está embasada em estudos de Reifschneider e Arny (1979), que pesquisaram sobre a possível transmissão de $K$. zeae pela semente, com inoculações de esporos do fungo em espigas de milho, 10 dias após a polinização, para posterior reisolamento da semente. Relataram a presença de $K$. zeae no embrião da semente e que alguns isolados obtidos foram reinoculados em plântulas de milho e apresentaram comportamento patogênico.

\section{Conclusão}

Portanto, concluiu-se que os híbridos de milho testados apresentaram diferentes graus de resistência a mancha ocular.

\section{Referências}

AGROCERES: guia Agroceres de sanidade. São Paulo: Sementes Agroceres, 1996.

ASSOCIAÇÃO PAULISTA DE PRODUTORES DE SEMENTES E MUDAS - APPS. Características agronômicas das cultivares de milho disponíveis no mercado na safra 2007/08. Disponível em: <http://www. apps.agr.br/upload/ax2_2703200842120900_tabela1. htm>. Acesso em: 09 out. 2008.

BHERING, S. B.; SANTOS, H. G. dos; BOGNOLA, I. A.; CÚRCIO, G. R.; MANZATTO, C. V.; CARVALHO
JUNIOR, W. de; CHAGAS, C. das; ÁGLIO, M. L. D.; SOUZA, J. S. de. Mapa de solos do Estado do Paraná: legenda atualizada. Rio de Janeiro: EMBRAPA/IAPAR, 2008. $74 \mathrm{p}$.

CAMOCHENA, R. C.; SANTOS, I. dos; MALAGI, G. Avaliação da sensibilidade de genótipos de milho à mancha ocular, causada por Kabatiella zeae. Fitopatologia Brasileira, Brasília, v. 32, n. 3, p. 225, 2007.

CAMOCHENA, R. C.; SANTOS, I. dos; MAZARO, S. M. Escala diagramática para avaliação da severidade da mancha ocular em milho causada por Kabatiella zeae. Ciência Rural, Santa Maria, v. 38, n. 8, p. 2124-2131, 2008.

CAVIGLIONE, J. H.; KIIHL, L. R. B.; CARAMORI, P. H.; OLIVEIRA, D. Cartas climáticas do Paraná. Londrina: IAPAR, 2000. CD-ROM.

CHIANG, M. S.; HUDSON, M. Inheritance of resistance to Kabatiella zeae eyespot of maize. Phytoprotection, Quebec, Canadá, v. 71, n. 3, p. 107-112, 1990.

DOURADO NETO, D.; FANCELLI, A. L. (Ed.). Produção de milho. Guaíba: Agropecuária. 2000.

ESTEVES, A. Incidência de doenças, sob condições de campo, em cultivares de milho (Zea mays), em Dourados. Fitopatologia Brasileira, Brasília, v. 9, n. 3, p. 155-160, 1984.

NAIBO, B.; THIERRY, J. The return of Kabatiellosis. Phytoma, Espanha, v. 1, n. 513, p. 24-25, 1999.

PREFEITURA MUNICIPAL DE PALMA SOLA. Características climáticas da cidade de Palma Sola. 2009. Disponível em: <http://www.palmasola.sc.gov.br/ conteudo/?item $=19907 \& \mathrm{fa}=6960$ > . Acesso em: 17 nov. 2009.

PRONCZUK, M.; BOJANOWSKI, J.; WARZECHAJ, R. Effect of Leaf infection by kabatiella zeae on stalk rot prevalence and grain yield of maize hybrids. Phytopathology, Saint Paul, v. 152, n. 7, p. 410-415, 2004.

REIFSCHNEIDER, F. J. B.; ARNY, D. C. Yeld loss of maize caused by Kabatiella zeae. Phytopathology, Saint Paul, v. 73, p. 607-609, 1983.

. Seed infection of maize (Zea mays) by Kabatiella zeae. Plant Disease Reporter, Madison, v. 63, n. 5, p. 352-354, 1979.

SANTOS, I. dos; CAMOCHENA, R. C.; MALAGI, G. Milho - mancha ocular é nova ameaça. Cultivar Grandes Culturas, Pelotas, v. 1, p. 20, 2007a.

SANTOS, I. dos; SILVA, A; MALAGI, G. Ocorrência de mancha ocular em milho causada por Kabatiella Zeae no Paraná e em Santa Catarina. Fitopatologia Brasileira, Brasília, v. 32, n. 3, p. 359, 2007 b. 